\title{
Photosynthetic activity of variegated leaves of Coleus $\times$ hybridus hort. cultivars characterised by chlorophyll fluorescence techniques
}

\author{
M. BOREK, R. BĄCZEK-KWINTA, and M. RAPACZ \\ Department of Plant Physiology, Faculty of Agriculture and Economics, University of Agriculture in Krakow \\ 30-239, Podtużna 3, Poland
}

\begin{abstract}
Different pigments often occur together and affect photosynthetic characteristics of the respective leaf portions. In this study, photosynthetic activity in variegated leaves of five cultivars of the ornamental and medicinal plant, Coleus $\times$ hybridus hort., was estimated by image analysis and point data measurements of major chlorophyll (Chl) fluorescence parameters and related to the amount of photosynthetic pigments measured with a Chl meter or spectrophotometrically in leaf extracts. Significant differences in Chl and carotenoid (Car) contents were noticed among differentially pigmented sectors of a leaf and among the cultivars. Although the higher Chl concentration was noticed in purple parts compared to green parts of the leaves, the values of minimal and maximal fluorescence yield at the dark- and light-adapted state $\left(\mathrm{F}_{0}\right.$, $\mathrm{F}_{\mathrm{m}}, \mathrm{F}_{0}{ }^{\prime}, \mathrm{F}_{\mathrm{m}}$ ', respectively) were a little lower than those in the green sectors, indicating photoprotective effects provided by anthocyanins and Car, more abundant in the red parts. The lowest $\mathrm{Chl}$ and Car content was detected in creamy-yellow and pink sectors and this contributed to low $F_{0}, F_{m}$, and $F_{m}^{\prime}$, maximal quantum yield of PSII photochemistry, and nonphotochemical and photochemical quenching but high PSII maximum efficiency and effective quantum yield of PSII photochemistry. Both methods of $\mathrm{Chl}$ fluorescence analysis revealed heterogeneity in capture, transfer, and dissipation of excitation energy but $\mathrm{Chl}$ fluorescence imaging was more suitable in examining very narrow pigmented leaf areas.
\end{abstract}

Additional key words: carotenoids; chlorophyll imaging; pigments.

\section{Introduction}

Coleus $\times$ hybridus hort. [syn. Coleus blumei Benth.; Plectranthus scutellarioides] is an ornamental garden plant. There are more than 500 varieties and cultivars of the species cultivated all over the world (Lebowitz 1985, Soni and Singhai 2012, Osman 2013). In recent years, it has become more popular due to a large number of cultivars with highly decorative and variegated leaves. The colours of Coleus foliage range from green, yellow, orange, and brown through purple to red and pink (Chung and Choi 2008, Osman 2013). Moreover, the leaves may differ in patterns (e.g. spots, flecks, mosaics), number of coloured sectors (e.g. bicoloured, tricoloured), shapes (e.g. narrow, wide, round, ovate), size, and even fancy edges. In addition to their decorative value, the plants may have medicinal properties thank to the presence of rosmarinic acid, an important phenolic compound exhibiting antiviral, antibacterial, anti-inflammatory, and antioxidant activity (Park et al. 2008).

Coleus leaf colour depends on the presence of pigments including Chls, Cars, flavonoids, anthocyanins, and betalains (Alkema and Seager 1982, Tanaka et al. 2008). In higher plants, Chl $a$ and $b$ and Cars are the pigments responsible for light harvesting, while $\mathrm{Chl} a$ passes absorbed light energy into the electron transport chain. Cars are accessory photosynthetic pigments involved in direct light harvesting (Młodzińska 2009, Khoo et al. 2011) and photoprotective functions (Bartley and Scolnik 1995, Yamamoto and Bassi 1996, Maxwell and

Received 10 April 2015, accepted 23 March 2013, published as online-first 12 April 2016.

${ }^{+}$Corresponding author; e-mail: rrbaczek@cyf-kr.edu.pl

Abbreviations: CA - Camaroon; Car(s) - carotenoid(s); CF - chlorophyll fluorescence; Chl - chlorophyll; DD - Dappled Down; $\mathrm{F}_{0}, \mathrm{~F}_{\mathrm{m}}$ - minimal and maximal fluorescence yield at the dark-adapted state; $\mathrm{F}_{0}{ }^{\prime}, \mathrm{F}_{\mathrm{m}}{ }^{\prime}$ - minimal and maximal fluorescence yield at the light-adapted state; $F_{t}$ - steady-state fluorescence yield; $F_{v}$ - variable fluorescence at the dark-adapted state; $F_{v} / F_{m}-$ maximal quantum yield of PSII photochemistry; FM - fresh mass; SD - standard deviation; NPQ - Stern-Volmer nonphotochemical quenching coefficient; NR - Neon Rose; qP - photochemical quenching coefficient; RU - Ruby; SR - Sunlover Red Ruffles; ФPSII - effective quantum yield of PSII photochemistry.

Aknowledgements: The study was supported by the University of Agriculture in Krakow, DS 3113.

“C The Author(s).” This article is published with open access at link.springer.com 
Johnson 2000). In autumn, they are also responsible for yellow colour of leaves normally masked by Chls. Based on their structure, Cars are divided into two major groups: orange-red carotenes, composed exclusively of carbon and hydrogen, and yellow-orange xanthophylls that also contain oxygen atoms (Goodwin 1980, Młodzińska 2009).

Anthocyanins are nonphotosynthetic pigments, but numerous studies have pointed out their photoprotective role. They are accumulated in vacuoles of adaxial epidermal or palisade parenchyma cells and act as a photoshield, especially in developing and senescing leaves as well as during exposure to intense light in combination with environmental stresses, such as low temperature or low nutrient availability (Gould 1995, Henry et al. 2012, Liakopoulos and Spanorigas 2012, Logan et al. 2015).

Noninvasive and rapid $\mathrm{Chl}$ fluorescence (CF) techniques offer highly accurate measurements that illustrate photosynthetic performance of plants. CF analysis is often used to investigate a plant response to various abiotic (in

\section{Materials and methods}

Plant material and its detailed characteristics: Plants of five variegated Coleus $x$ hybridus hort. cultivars: 'Dappled Down' (DD), 'Camaroon' (CA), 'Ruby’ (RU), 'Sunlover Red Ruffles' (SR), and 'Neon Rose' (NR) were used in all the experiments presented in this study. DD plants had medium-large, green leaves with creamy-yellow or white sectors near the veins. The edges of their foliage were surrounded by arrow-shaped tips. The specimens of CA had medium-size leaves with creamy centres and wide, green outer margins. Plants of RU had purple foliage with narrow pink centres near the main vein and large, green borders. SR specimens were similar to RU in their pigmentation, although their pink sectors were larger than those of RU, and the green fragments formed very narrow outline located mainly at the base of the leaf and/or on the arrow-shaped tips. The leaves of NR had purple centres surrounded by a wide, two-tone border of bright green and yellow (Fig. 1).

Growth conditions: The plants were produced from cuttings and grew in pots filled with a commercial garden soil under natural light [14-h day with a natural light intensity of $400-500 \mu \mathrm{mol}$ (quanta) $\mathrm{m}^{-2} \mathrm{~s}^{-1}$ ], in a greenhouse. The temperature was $20-23^{\circ} \mathrm{C}$ (day) and $17-20^{\circ} \mathrm{C}$ (night), and the relative humidity (RH) was approx. $30 \%$. All specimens were free from any disease or nutrient shortage.

Measurements and analyses: All the measurements and analyses were performed on the leaf areas differing in pigmentation, in 5-7 biological replicates (one plant was used for all types of analyses, and the number of plants was 5-7). Green, creamy-yellow, purple, pink, and yellowgreen sectors were studied. Photosynthetic activity was estimated based on the analysis of images and numeric data particular, high-light intensity, heavy metals, drought, low temperature) and biotic stresses (e.g. herbivore or pathogen attack), and to assess plant stress tolerance (Nedbal et al. 2000, Pineda et al. 2008, Takayama et al. 2011, Borek et al. 2012, Dos Anjos et al. 2012, Muniz et al. 2014). The aim of this study was to determine the actual state of photosynthetic apparatus in differentially pigmented leaves. As fluorescence imaging also offers the possibility to screen gradients and irregularities of $\mathrm{CF}$ signatures over the whole leaf area (Lichtenthaler et al. 2000, Borek et al. 2012), its use seemed to be justified in the research on differentially pigmented leaves.

Given the specificity of multicoloured leaves of Coleus $\times$ hybridus hort. cultivars, our goal was to investigate the mechanisms of capture, transfer, and dissipation of excitation energy within an individual leaf with green, red, pink, and creamy-yellow coloration. This was achieved by employing $\mathrm{CF}$ imaging and point data measurements.

of major CF parameters. Physiological background to these data were the analyses of the main photosynthetic pigments.

Chl content: Relative Chl content was measured photometrically with a portable $\mathrm{Chl}$ meter (Cl-01, Hansatech, UK), and determined using dual wavelength optical absorbance (620 and $920 \mathrm{~nm})$. The results were expressed as "chlorophyll index" or "greenness index" (Cassol et al. 2008).

Photosynthetic pigment content assay: $\mathrm{Chl} a, \mathrm{Chl} b$, and Car content assays were performed according to Lichtenthaler (1987). Tissue samples of the same pigmentation were cut with a razor from mature (developed but not senescing) variegated leaves, weighed, and frozen in liquid nitrogen. The samples $(50 \mathrm{mg})$ were homogenized in $5 \mathrm{ml}$ of $96 \%$ ethanol and stored on ice, in darkness. The homogenates were centrifuged at $4^{\circ} \mathrm{C}$ for $5 \min (3,000 \times g)$, and the supernatants were used for the spectrophotometric analysis (Rayleigh UV-1800 UV/VIS, China). The absorbance was determined at $649 \mathrm{~nm}, 664 \mathrm{~nm}$, and $470 \mathrm{~nm}$.

Chl $\boldsymbol{a}$ fluorescence imaging: Fluorescence images of the leaf surface were obtained using Chl fluorescence imaging system (FluorCam 701 MF, PSI, Brno, Czech Republic). Leaves of different plants $(n=5-7)$ of each cultivar were cut and immediately placed in darkness inside a measuring chamber. $\mathrm{CF}$ images were captured at $22^{\circ} \mathrm{C}$ according to an experimental protocol consisting of 20 min dark adaptation and measurements of $\mathrm{F}_{0}$ (minimal fluorescence - CF yield after dark adaptation, when all of the PSII reaction centres and electron acceptor molecules are fully oxidised), and $\mathrm{F}_{\mathrm{m}}$ [maximum fluorescence yield in darkadapted samples measured after light-saturating pulse of about $1,800 \mu \mathrm{mol}$ (photon) $\mathrm{m}^{-2} \mathrm{~s}^{-1}$ provided by halogen 
light source]. Then, orange actinic light $(620 \mathrm{~nm})$ of 1,000 $\mu$ mol(photon) $\mathrm{m}^{-2} \mathrm{~s}^{-1}$ was switched on for $400 \mathrm{~s}$. Saturating pulses [approx. 1,800 $\mu \mathrm{mol}$ (photon) $\mathrm{m}^{-2} \mathrm{~s}^{-1}$ ] were repeated every $25 \mathrm{~s}$, which was sufficient to stabilize steady-state fluorescence yield $\left(\mathrm{F}_{\mathrm{t}}\right)$, and $\mathrm{F}_{\mathrm{m}}{ }^{\prime}$ (maximum fluorescence yield in light-adapted samples) was measured during the last pulse. $\mathrm{F}_{0}{ }^{\prime}$ (minimal fluorescence of lightadapted leaves) was recorded after $3 \mathrm{~s}$ of far red light illumination after the actinic light had been switched off. The images were processed by the internal software of the equipment (Fluorcam v. 5.0). Maximum efficiency of PSII photochemistry was calculated as $F_{v} / F_{m}$, where $F_{v}=F_{m}-F_{0}$. PSII antenna trapping efficiency was calculated as $\mathrm{F}_{\mathrm{v}}{ }^{\prime} / \mathrm{F}_{\mathrm{m}}{ }^{\prime}$, where $\mathrm{F}_{\mathrm{v}}{ }^{\prime}=\mathrm{F}_{\mathrm{m}}{ }^{\prime}-\mathrm{F}_{0}{ }^{\prime}$. Effective quantum yield of PSII photochemistry $\left(\Phi_{\mathrm{PSII}}\right)$ was calculated according to Maxwell and Johnson $(2000)$ as $\left(F_{m}{ }^{\prime}-F_{t}\right) / F_{m}{ }^{\prime}$, where $F_{t}=$ the steady state fluorescence under actinic light prior to a saturating pulse. Photochemical quenching coefficient was calculated according to Schreiber et al. $(1986): \mathrm{q}_{\mathrm{P}}=\left(\mathrm{F}_{\mathrm{m}}{ }^{\prime}-\mathrm{F}_{\mathrm{t}}\right) /\left(\mathrm{F}_{\mathrm{m}}{ }^{\prime}-\mathrm{F}_{0}{ }^{\prime}\right)$. Stern-Volmer nonphotochemical quenching was expressed as NPQ $=\left(F_{m}-F_{m}{ }^{\prime}\right) / F_{m}{ }^{\prime}$ (Bilger and Björkman 1991). The most representative images were presented.

Chl $\boldsymbol{a}$ fluorescence point data measurements: To confirm the results of $\mathrm{CF}$ imaging, numeric CF parameters were measured by FMSII pulse-amplitude modulated fibre-optic system (Hansatech, Kings Lynn, UK). The calculations for the parameters were the same as in the case

\section{Results}

The analysis of the photosynthetic pigments showed differences in the amount of Chls and Cars, as well as in their ratios within variegated leaves of Coleus plants of the different cultivars (Table 1). As expected, the green parts of the DD and CA leaves had much higher content of total Chl than the creamy-yellow areas. It was confirmed by both leaf greenness index (measured with a Chl meter) and the spectrophotometric analyses, although the difference range reflected by the $\mathrm{Chl}$ index was much greater than the values of spectrophotometrically measured $\mathrm{Chl} a+b(\mathrm{Chl}$ index: the values 31-140 times higher, spectrophotometric assays: 3-4 times higher in favour of the green areas). The $\mathrm{Chl} a / b$ ratio in the creamy-yellow sectors was approximately five times lower compared to the green parts, and this was caused by a greater amount of $\mathrm{Chl} b$ in relation to Chl $a$. Besides, the total Car content was below detection limits.

Interestingly, the purple areas of RU and SR leaves contained 2-4 times greater amount of total Chls than that of the green ones, as revealed by both methods (Table 1). The differences in the $\mathrm{Chl}$ index were larger than those obtained from the extraction method but not as large as in the case of green and creamy-yellow cultivars. In the pink areas, Chls were present at very low concentrations of CF imaging. Leaf clips (with a 5-mm diameter hole) were fastened on the leaf areas with the same pigmentation on the same plants used for CF imaging. After $20 \mathrm{~min}$ of dark adaptation, $\mathrm{F}_{0}$ was measured and a saturating-light pulse $\left[10,000 \mu \mathrm{mol}\right.$ (photon) $\mathrm{m}^{-2} \mathrm{~s}^{-1}$ for $\left.0.9 \mathrm{~s}\right]$ was used to determine $F_{m}$. Next, the leaf was irradiated with the actinic light $\left[1,500 \mu \mathrm{mol}\left(\right.\right.$ photon) $\left.\mathrm{m}^{-2} \mathrm{~s}^{-1}\right]$ for $270 \mathrm{~s}$, which was sufficient to measure steady state fluorescence $\left(F_{t}\right)$. Then, the saturating-light pulse was used again to determine the $\mathrm{F}_{\mathrm{m}}$ '. After turning the actinic light off, $\mathrm{F}_{0}{ }^{\prime}$ was measured by immediately irradiating the leaf for $3 \mathrm{~s}$ with a far red emitting diode (radiation of about $15 \mathrm{~W} \mathrm{~m}^{-2}$ ). The source of a modulation beam (duration pulses $1.8 \mu \mathrm{s}, 2.3 \mathrm{kHz}$ ) was an amber LED [peak wavelength $594 \mathrm{~nm}$, PFD ca. $0.05 \mu \mathrm{mol}$ (photon) $\mathrm{m}^{-2} \mathrm{~s}^{-1}$ ]. Actinic and pulse irradiations were provided by a halogen lamp $(20 \mathrm{~W})$. The signal detector was a PIN photodiode with a long-pass filter $(>700 \mathrm{~nm})$, and the sampling rate was $10-20 \mathrm{kHz}$ (depending on the instrument mode).

Statistical analysis: All the measurements were performed on 5-7 replicates $(n=5-7)$. The data were subjected to an analysis of variance (ANOVA). Differences between means were compared using the Student's $t$-test (for two means) and Duncan's test (for three means). The differences were considered significant if $P$ was at least $\leq$ 0.05 . All the analyses were carried out using Microsoft Office Excel 2003 and the Statistica 9.0.

(extremely low when the Chl index was measured), the total Car content was undetectable, and similarly to the creamy-yellow areas (of DD and CA), the pink ones had a higher concentration of $\mathrm{Chl} b$ than $\mathrm{Chl} a$.

In the purple leaf areas of NR plants, the Chl index was four times higher than in the yellow-green ones, which was partially confirmed by the spectrophotometric analyses and was due to the higher amount of Chl $a$ in the purple areas (Table 1).

The images of minimal fluorescence yield for dark- and light-adapted leaves $\left(\mathrm{F}_{0}\right.$ and $\mathrm{F}_{0}$ ', respectively) in the DD and CA plants showed significant differences between the green and creamy-yellow sectors (Fig. 1), and this was confirmed by the numeric data (Table 2 ). These parameters were very low in the creamy parts when compared to the green ones. Additionally, the images of $\mathrm{F}_{0}$ ' revealed that the values of this parameter were heterogeneously distributed within the green sectors of the CA leaves, with the highest intensity recorded near the top of the leaf (Fig. 1). Similar results were obtained for $F_{m}$ and $F_{m}$ ' (Table 2, Fig. 1).

The images of $F_{v} / F_{m}$ in the DD and CA leaves revealed lower values in the creamy-yellow sectors than in the green ones (Fig. 1). In the case of DD, the CF imaging results were not confirmed by the point data measurements as the 
Table 1. The $\mathrm{Chl}$ index and the content of photosynthetic pigments and $\mathrm{Chl} a / b$ ratio in variegated leaves of plants of Coleus cultivars. Mean $\pm \mathrm{SD}, n=5-7$. The means labelled with the same letter are not significantly differentiated $(P<0.05$; paired Student's $t$-test or Duncan's test). DD - Dappled Down, CA - Camaroon, RU - Ruby, SR - Sunlover Red Ruffles, NR - Neon Rose, ${ }^{1}-$ below detection limits.

\begin{tabular}{llllllll}
\hline Cultivar & Leaf colour & $\begin{array}{l}\text { Chl index } \\
{[\text { relative unit }]}\end{array}$ & $\begin{array}{l}\text { Chl }(a+b) \\
{\left[\mu \mathrm{g} \mathrm{g}^{-1}(\mathrm{FM})\right]}\end{array}$ & $\begin{array}{l}\text { Chl } a \\
{\left[\mu \mathrm{g} \mathrm{g}^{-1}(\mathrm{FM})\right]}\end{array}$ & $\begin{array}{l}\text { Chl } b \\
{\left[\mu \mathrm{g} \mathrm{g}^{-1}(\mathrm{FM})\right]}\end{array}$ & $\begin{array}{l}\text { Car } \\
{\left[\mu \mathrm{g} \mathrm{g}^{-1}\left(\mathrm{FM}^{2}\right]\right.}\end{array}$ & $\begin{array}{l}\text { Chl } a / b \\
{\left[\mu \mathrm{g} \mathrm{g}{ }^{-1}(\mathrm{FM})\right]}\end{array}$ \\
\hline DD & Green & $2.81 \pm 0.54^{\mathrm{a}}$ & $332.72 \pm 42.98^{\mathrm{a}}$ & $232.37 \pm 32.50^{\mathrm{a}}$ & $100.36 \pm 11.26^{\mathrm{a}}$ & $56.38 \pm 7.02$ & $2.31 \pm 0.13^{\mathrm{a}}$ \\
& Creamy-yellow & $0.02 \pm 0.03^{\mathrm{b}}$ & $78.78 \pm 27.85^{\mathrm{b}}$ & $23.85 \pm 9.11^{\mathrm{b}}$ & $54.93 \pm 18.84^{\mathrm{b}}$ & $\approx 0^{1}$ & $0.43 \pm 0.03^{\mathrm{b}}$ \\
CA & Green & $7.74 \pm 2.26^{\mathrm{a}}$ & $284.32 \pm 31.54^{\mathrm{a}}$ & $207.63 \pm 21.27^{\mathrm{a}}$ & $76.69 \pm 11.13^{\mathrm{a}}$ & $54.08 \pm 5.21$ & $2.72 \pm 0.19^{\mathrm{a}}$ \\
& Creamy-yellow & $0.25 \pm 0.24^{\mathrm{b}}$ & $86.03 \pm 59.18^{\mathrm{b}}$ & $35.56 \pm 15.30^{\mathrm{b}}$ & $50.47 \pm 30.98^{\mathrm{b}}$ & $\approx 0^{1}$ & $0.70 \pm 0.12^{\mathrm{b}}$ \\
RU & Green & $2.17 \pm 0.32^{\mathrm{b}}$ & $351.55 \pm 28.31^{\mathrm{b}}$ & $245.47 \pm 19.95^{\mathrm{b}}$ & $106.08 \pm 9.76^{\mathrm{b}}$ & $59.83 \pm 6.09^{\mathrm{a}}$ & $2.32 \pm 0.13^{\mathrm{a}}$ \\
& Purple & $8.06 \pm 0.67^{\mathrm{a}}$ & $446.61 \pm 40.52^{\mathrm{a}}$ & $295.48 \pm 24.56^{\mathrm{a}}$ & $151.13 \pm 16.08^{\mathrm{a}}$ & $62.01 \pm 6.18^{\mathrm{a}}$ & $1.96 \pm 0.05^{\mathrm{b}}$ \\
& Pink & $0.28 \pm 0.12^{\mathrm{c}}$ & $67.18 \pm 1.32^{\mathrm{c}}$ & $26.76 \pm 2.99^{\mathrm{c}}$ & $40.42 \pm 2.30^{\mathrm{c}}$ & $\approx 0^{1}$ & $0.67 \pm 0.11^{\mathrm{c}}$ \\
SR & Green & $3.44 \pm 0.81^{\mathrm{b}}$ & $290.91 \pm 49.54^{\mathrm{b}}$ & $198.49 \pm 40.34^{\mathrm{b}}$ & $92.42 \pm 9.77^{\mathrm{b}}$ & $47.26 \pm 11.23^{\mathrm{b}}$ & $2.13 \pm 0.25^{\mathrm{a}}$ \\
& Purple & $6.99 \pm 0.37^{\mathrm{a}}$ & $375.34 \pm 24.37^{\mathrm{a}}$ & $253.27 \pm 11.47^{\mathrm{a}}$ & $122.07 \pm 16.81^{\mathrm{a}}$ & $57.73 \pm 4.93^{\mathrm{a}}$ & $2.11 \pm 0.29^{\mathrm{a}}$ \\
& Pink & $0.04 \pm 0.04^{\mathrm{c}}$ & $62.11 \pm 18.80^{\mathrm{c}}$ & $22.12 \pm 8.02^{\mathrm{c}}$ & $39.99 \pm 12.36^{\mathrm{c}}$ & $\approx 0^{1}$ & $0.56 \pm 0.16^{\mathrm{b}}$ \\
NR & Yellow-green & $0.84 \pm 0.38^{\mathrm{b}}$ & $212.68 \pm 66.96^{\mathrm{a}}$ & $124.93 \pm 18.26^{\mathrm{b}}$ & $81.76 \pm 50.93^{\mathrm{a}}$ & $36.03 \pm 3.68^{\mathrm{a}}$ & $1.54 \pm 0.57^{\mathrm{a}}$ \\
& Purple & $3.27 \pm 0.74^{\mathrm{a}}$ & $292.63 \pm 14.93^{\mathrm{a}}$ & $177.82 \pm 11.09^{\mathrm{a}}$ & $91.80 \pm 1.94^{\mathrm{a}}$ & $41.00 \pm 5.14^{\mathrm{a}}$ & $1.93 \pm 0.17^{\mathrm{a}}$ \\
\hline
\end{tabular}

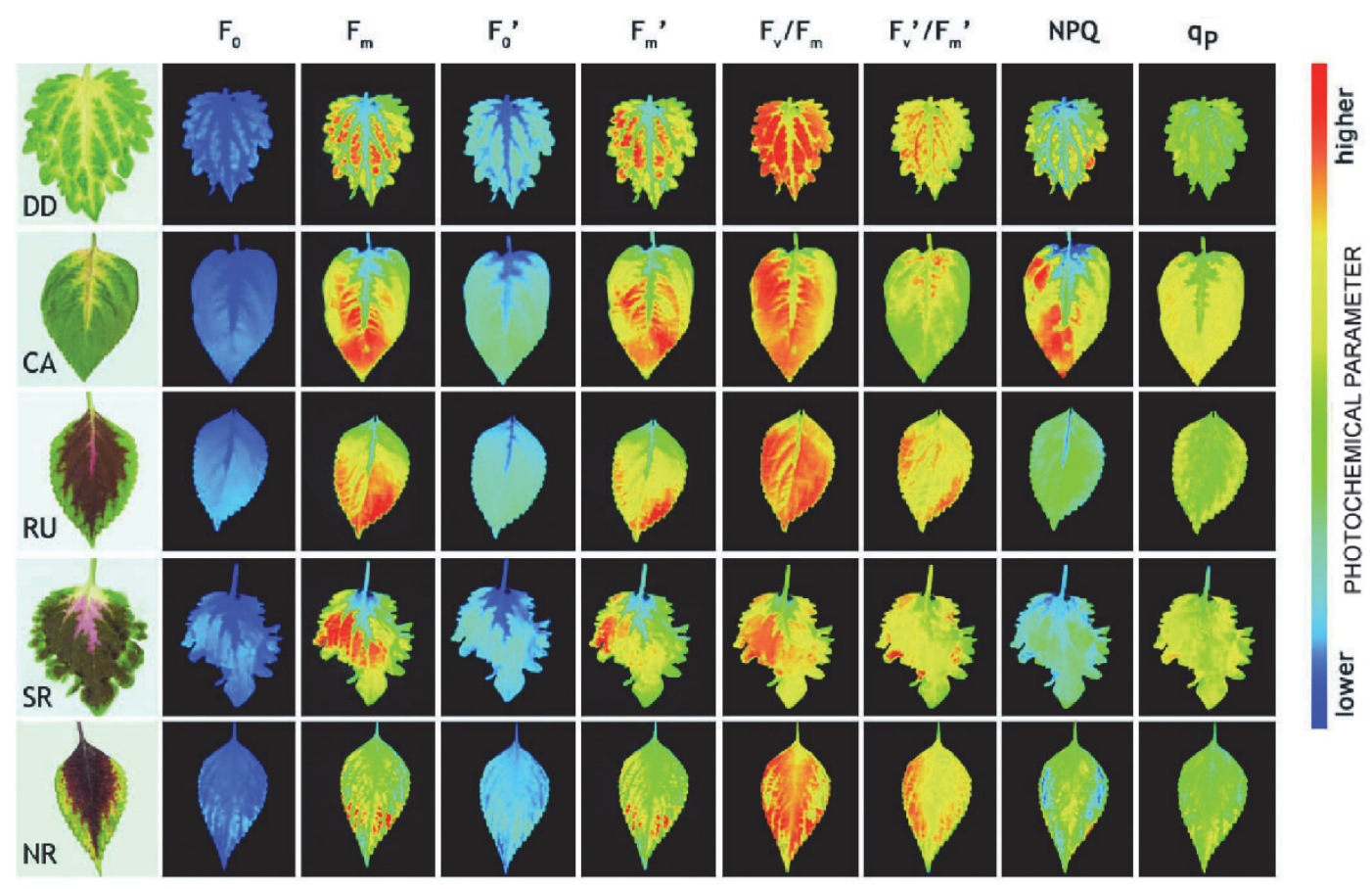

Fig. 1. Chl fluorescence images of $\mathrm{F}_{0}, \mathrm{~F}_{\mathrm{m}}, \mathrm{F}_{0}{ }^{\prime}, \mathrm{F}_{\mathrm{m}}{ }^{\prime}, \mathrm{F}_{\mathrm{v}} / \mathrm{F}_{\mathrm{m}}, \mathrm{F}_{\mathrm{v}}{ }^{\prime} / \mathrm{F}_{\mathrm{m}}$ ', NPQ, and $\mathrm{qP}$ in variegated leaves of Coleus $\times$ hybridus hort. All images are representative for all studied plants $(n=5)$. DD - 'Dappled Down', CA - 'Camaroon', RU - 'Ruby', SR - 'Sunlover Red Ruffles', NR - 'Neon Rose'. Coloured bar parallel to the images shows the range of values and how they mapped to the colour palette.

difference was statistically insignificant (Table 2). On the other hand, the image analysis of $\mathrm{F}_{\mathrm{v}}{ }^{\prime} / \mathrm{F}_{\mathrm{m}}{ }^{\prime}$ in the $\mathrm{DD}$ and $\mathrm{CA}$ plants showed that higher PSII antenna trapping efficiency was detected mainly on the border between the green and yellow-pigmented sectors (Fig. 1).

In the case of NPQ, distinct differences in CF between the green and creamy-yellow areas were noticed in the leaves of DD and CA (Fig. 1, Table 1). In the CA leaves, the NPQ image resembled that of $F_{m}$ and $F_{m}$ ', revealing heterogeneity of the parameters within the green area. $\mathrm{q}_{\mathrm{P}}$ in the DD leaves was low, as indicated by both CF imaging and measurements, especially in the case of the creamyyellow sectors (Fig. 1, Table 1). $\mathrm{q}_{\mathrm{P}}$ in the CA leaves was higher than in DD ones, and higher in the green parts than in the creamy-yellow areas (Fig. 1, Table 2). The green sectors of the CA leaves showed also the highest NPQ and 


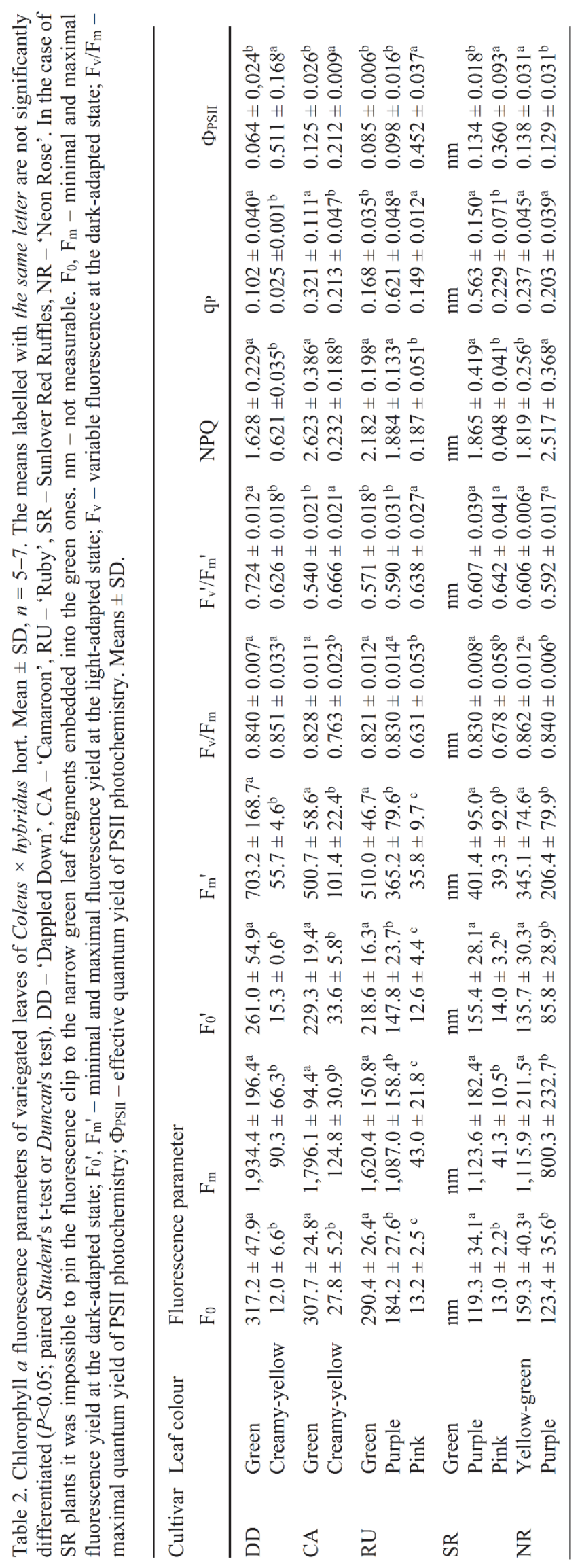


qp amongst the studied cultivars (Fig. 1, Table 2).

The images of the pink sectors of the RU and SR cultivars indicated low values of individual parameters when compared to the green and/or purple parts (Fig. 1), except for the $\mathrm{F}_{\mathrm{v}}{ }^{\prime} / \mathrm{F}_{\mathrm{m}}$ ' parameter. These data were usually confirmed by the point data measurements (Table 2).

An image-based comparison of the green and purple sectors in the RU and SR plants showed no differences in $\mathrm{F}_{0}$ and $\mathrm{F}_{0}{ }^{\prime}$, but the point data measurements revealed that these parameters had higher values in the green parts than in the purple ones (Table 2). In the RU plants, similar results were obtained in the case of $F_{m}$ and $F_{m}{ }^{\prime}$. In the SR leaves, the imaging of $F_{m}$ and $F_{m}$ ' revealed heterogeneity within the leaf but it was impossible to compare the images with the numeric data on CF parameters because the green leaf sectors were embedded into the purple ones and too narrow for the clip to be properly positioned.

Neither the images of $F_{v} / F_{m}, F_{v}{ }^{\prime} / F_{m}{ }^{\prime}$, and NPQ nor their corresponding numeric data showed differences between the green and purple areas of the RU plants. However, the green parts had higher $\mathrm{CF}$ imaging and point data values of $\mathrm{q}_{\mathrm{P}}$ than the other ones (Fig. 1, Table 2).

In the SR plants, heterogeneity of $\mathrm{F}_{\mathrm{v}}{ }^{\prime} / \mathrm{F}_{\mathrm{m}}{ }^{\prime}$ ratio within

\section{Discussion}

The Chl index and standard Chl spectrophotometric assay revealed differences between different areas of Coleus leaves, but some discrepancies in the range of these differences were obtained. It has been known, however, that the relationship between these two methods is nonlinear, and may vary upon the anatomical features of the leaves, the amount of chloroplasts within the mesophyll and nonuniform distribution of radiation across the leaf (Uddling et al. 2007, Cassol et al. 2008). Not only the "sieve effect", but also interference from the anthocyanins to the Chl index measurements is possible. Although $C L-01$ measurements were performed at 620 and $940 \mathrm{~nm}$, i.e. at the wavelengths not absorbed by these pigments, whose peak absorbance is $500-550 \mathrm{~nm}$ (Landi et al. 2015), it has been proved that absorption of anthocyanins in vivo can be shifted toward the region above $600 \mathrm{~nm}$ (Merzlyak et al. 2008, Hlavinka et al. 2013). For correcting the readings of SPAD and NDVI Chl meters in order to eliminate such contributions to measurements, a model was proposed by Hlavinka et al. (2013).

Irrespective of the discrepancy between the methods, the results indicated that $\mathrm{Chl}$ occurred in all variegated sectors of Coleus leaves but in different amounts and different $\mathrm{Chl} a / b$ ratios. The lowest $\mathrm{Chl}$ content was noticed in the creamy-yellow and pink parts, irrespective of the method. Similar results were obtained by Hung and Xie (2009) in pale yellow plants regenerated from a variegated Epipremnum aureum. The highest contents of Chls were present not in the green parts but in their purple counterparts, similarly to differentially pigmented varieties of Pelargonium $\times$ hortorum (Liakopoulos and both areas was noticed (Fig. 1), but the difference was insignificant (Table 2). Such heterogeneity was also observed in the case of NPQ and $\mathrm{q}_{\mathrm{P}}$, but their values were usually higher in the red than in the pink areas (Fig. 1), and the point data measurements confirmed the differences (Table 2).

The values of $F_{0}, F_{m}, F_{0}{ }^{\prime}, F_{m}{ }^{\prime}$, and $F_{v} / F_{m}$ in the yellowgreen areas of the NR cultivar were higher as compared to the purple parts (Table 2, Fig. 1). Although the point data measurements of $\mathrm{F}_{\mathrm{v}}{ }^{\prime} / \mathrm{F}_{\mathrm{m}}{ }^{\prime}$ and $\mathrm{q}_{\mathrm{P}}$ parameters in the leaves of this cultivar did not show differences between the examined areas (Table 2), the results of CF imaging indicated higher values in the yellow-green areas than in the purple ones, and in the case of NPQ an opposite result was obtained (Fig. 1).

The values of the effective quantum yield of PSII photochemistry $\left(\Phi_{\mathrm{PSII}}\right)$ were much higher in the creamyyellow (DD, CA) and purple (RU) parts of the leaves than in the green ones (Table 2). They were also higher within the pink areas of SR compared to the purple ones. Contrary to RU, a slight difference in favour of the yellow-green NR parts $v s$. the purple ones was also noticed (Table 2).

Spanorigas 2012). An unusually high amount of Chl $a$ and $b$ and anthocyanins in the surface layers of the mesophyll was also found in black-pigmented leaves of Ophiopogon planiscapus 'Nigrescens' (Hatier and Gould 2007).

Numerous studies indicated that the increased $\mathrm{Chl}$ content in red-leafed plants is associated with the lower Chl $a / b$ ratio similarly to the shade-adapted ones (Björkman 1981, Anderson 1986, Porra 2002, Hughes and Smith 2007, Nielsen and Simonsen 2011, Liakopoulos and Spanorigas 2012). The variation in the $\mathrm{Chl} a / b$ ratio is due to the differences in PSI to PSII ratio as well as the size and composition of the LHCs associated with each photosystem and containing different amounts of Chl $b$ (Zhu et al. 2003, Wentworth et al. 2006). In the case of the purple-pigmented sectors, our experiments revealed similar result only for the RU plants, but it should be emphasised that Coleus is a species requiring not low but high irradiance (Garland 2009, and personal observations, unpublished). In the creamy-yellow and pink sectors, the $\mathrm{Chl} a / b$ ratio was markedly lower and within the small pool of Chls, Chl $b$ was more abundant than $\mathrm{Chl} a$, which is unusual (Kim et al. 2009). The presence of protochlorophyllides may be an explanation, because they have the absorbance spectra similar to $\mathrm{Chl} b$ (Belyayeva and Litvin 2011, Gabruk et al. 2015).

Cars are associated with Chls, being bound to the pigment-protein complexes of photosystems, with the majority of xantophylls found in LHCs and $\beta$-Car in the core complexes (Yamamoto and Bassi 1996, Matsubara et al. 2009). In the present study, Cars were undetectable in the creamy-yellow and pink sectors of Coleus leaves that 
contained only small amounts of Chls. However, it does not necessarily mean that these parts of the leaves are devoid of these pigments. They may contain extremely low concentrations of Car (below detection limit) or/and colourless Car such as phytoene that was found in white sectors of variegated Arabidopsis thaliana mutants (Wetzel et al. 1994, Wu et al. 1999, Foudree et al. 2012).

The pigment content is the basis for the interpretation of some CF parameters, and then venturing estimation of the physiological state of photosynthetic apparatus (Lichtenthaler et al. 2000, Baker 2008, Bączek-Kwinta et al. 2011, Muniz et al. 2014). In the creamy-yellow and pink sectors of leaves, the values of $F_{0}, F_{m}, F_{0}{ }^{\prime}$, and $F_{m}{ }^{\prime}$ were very low when compared to the other areas due to the low content of photosynthetic pigments. Other parameters, such as $F_{\mathrm{v}} / \mathrm{F}_{\mathrm{m}}, \mathrm{q}_{\mathrm{P}}$, and NPQ, in these parts also remained low indicating diminished photochemical capacity of PSII, low amount of PSII reaction centres, and less energy available due to the lack of Cars or their small amount, respectively (Demmig and Björkmann 1987, Krause and Weis 1991, Sofo et al. 2009). These results, together with high $\Phi_{\text {PSII }}$ and $\mathrm{F}_{\mathrm{v}}{ }^{\prime} / \mathrm{F}_{\mathrm{m}}$ ' in these areas, may be interpreted as better light energy utilization for photochemistry by the lowered number of functioning PSII reaction centres, as demonstrated in a model by Miyata et al. (2012).

Many studies comparing photosynthesis in green and red-leafed plants yielded conflicting results but this could be caused by a different plant (or leaf) age or whether the anthocyanic pigmentation is a feature resulting from the light conditions or, in case of some ornamentals, a result of breeding. For example, red juvenile leaves of Syzygium had lower photosynthetic capacity as compared to green ones (Dodd et al. 1998). A similar relationship was noticed in the case of red and green leaves of Quintinia serrata, but other studies showed higher photosynthetic capacity in the red plants when measured as $\mathrm{CO}_{2}$ assimilation (Gould et al. 1995, 2002; Liakopoulos et al. 2006, Nielsen and Simonsen 2011). Our research showed that in the purple, green, and yellow-green parts of Coleus leaves the values of most of the studied parameters were usually maintained at a high level. Nevertheless, slight differences between these differentially pigmented sectors were noticed. First of all, although the purple areas contained the highest amount of photosynthetic pigments, $\mathrm{F}_{0}, \mathrm{~F}_{\mathrm{m}}, \mathrm{F}_{0}{ }^{\prime}$, and $\mathrm{F}_{\mathrm{m}}{ }^{\prime}$ parameters were a little lower than those in the green and yellow-green sectors due to the high content of Cars and the presence of anthocyanins. Both groups of pigments participate in photoprotection but their mode of action may be either similar or different. While Cars dissipate energy as heat, the effect of anthocyanins is light attenuating (shading) of the photosynthetic tissue (Neill and Gould 2003, Nielsen and Simonsen 2011, Liakopoulos and Spanorigas 2012, Henry et al. 2012, Logan et al. 2015). In Coleus, anthocyanins are accumulated on the adaxial surface of the leaves, and provide photoprotection to LHC (Burger and Edwards 1996, Henry et al. 2012, Logan et al. 2015). Anthocyanins may participate in photoprotection through their antioxidant capacity, and some are capable of absorbing parts of the UV spectra similarly to the Cars (Neill and Gould 2003, Khoo et al. 2011, Takahashi and Badger 2011). In the absence of anthocyanins, green leaves utilise thermal energy dissipation via the xanthophyll cycle (Henry et al. 2012, Logan et al. 2015). In our experiment, it can be reflected by high NPQ values, and according to many authors (Maxwell and Johnson 2000, Montanaro et al. 2007, Sofo et al. 2009, BączekKwinta et al. 2011), it can be related to energy dissipation as heat via the xanthophyll cycle and other Cars, as well as conformational changes in PSII antennae (LHC).

Conclusion: Both methods of CF analysis revealed a heterogeneity in leaf $\mathrm{CF}$ parameters within a leaf that allowed for distinguishing the mechanisms responsible for capture, transfer, and dissipation of excitation energy in differentially pigmented sectors. In the case of very narrow pigmented leaf areas, CF imaging was more suitable than the point data measurements. Summing up the results, the green parts had the highest qp and usually high NPQ revealing relatively high light utilisation for photosynthesis but also the involvement of photoprotective mechanism based on thermal energy dissipation by carotenoids. In the red leaf sectors, the Cars content was even higher, and also the shading effect of anthocyanins was manifested by lower $\mathrm{q}_{\mathrm{P}}$ despite the high $\mathrm{Chl}$ content. The creamy-yellow and pink areas were characterized by the lowest contents of pigments and greatly diminished Chl $a / b$, but $\Phi_{\text {PSII }}$ and $\mathrm{F}_{\mathrm{v}}{ }^{\prime} / \mathrm{F}_{\mathrm{m}}{ }^{\prime}$ were high, indicating better light energy utilisation for photochemistry by diminished number of functioning PSII reaction centres.

Open Access This article is distributed under the terms of the Creative Commons Attribution License which permits any use, distribution, and reproduction in any medium, provided the original author(s) and the source are credited.

\section{References}

Alkema J., Seager L.: The chemical pigments of plants-chemical supplement. - J. Chem. Education 59: 183-186, 1982.

Anderson J.M.: Photoregulation of the composition, function and structure of thylakoid membranes. - Annu. Rev. Plant Physiol. 37: 93-136, 1986.

Baker N.R.: Chlorophyll fluorescence: a probe of photosynthesis in vivo. - Annu. Rev. Plant Biol. 59: 89-113, 2008.

Bartley G.E, Scolnik P.A.: Plant carotenoids: Pigments for photoprotection, visual attraction, and human health. - Plant Cell 7: 1027-1038, 1995.

Bączek-Kwinta R., Kozieł A., Seidler-Łożykowska K.: Are the fluorescence parameters of German chamomile leaves the first 
indicators of the anthodia yield in drought conditions? Photosynthetica 49: 87-97, 2011.

Belyaeva O.B, Litvin F.F.: Advances in understanding of the primary reactions of protochlorophyll(ide) photoreduction in cells and model systems. - J. Biophys. Chem. 2: 1-9, 2011.

Bilger W., Björkman O.: Temperature-dependence of violaxanthin deepoxidation and nonphotochemical fluorescence quenching in intact leaves of Gossypium hirsutum L. and Malva parviflora L. - Planta 184: 226-234, 1991.

Björkman O.: Responses to different quantum flux densities. In: Lange O.L., Nobel P.S, Osmond C.B., Ziegler H. (ed.): Physiological Plant Ecology. Vol. 1. Responses to the Physical Environment. Pp. 57-108. Springer Verlag, Berlin 1981.

Borek M., Bączek-Kwinta R., Rapacz M. Chlorophyll fluorescence imaging of cadmium-treated white cabbage plants. Web of Conferences 1: 39004, 2012.

Burger J., Edwards G.E. Photosynthetic efficiency, and photodamage by UV and visible radiation, in red versus green leaf coleus varieties. - Plant Cell Physiol. 37: 395-399, 1996.

Cassol D., de Silva F.S.P, Falqueto A.R. et al.: An evaluation of nondestructive methods to estimate total chlorophyll content. Photosynthetica 46: 634-636, 2008.

Chung B.N., Choi G.S.: Incidence of Coleus blumei viroid 1 in seeds of commercial Coleus in Korea. - Plant Pathol. J. 24: 305-308, 2008.

Demmig B., Björkman O.: Comparison of the effect of excessive light on chlorophyll fluorescence $(77 \mathrm{~K})$ and photon yield of $\mathrm{O}_{2}$ evolution in leaves of higher plants. - Planta 171: 171-184, 1987.

Dodd I.C., Critchley C., Woodall G.S., Stewart G.R.: Photoinhibition in differently coloured juvenile leaves of Syzygium species. - J. Exp. Bot. 49: 1437-1445, 1998.

Dos Anjos L., Oliva M.A, Kuki K.N.: Fluorescence imaging of light acclimation of brazilian atlantic forest tree species. Photosynthetica 50: 95-108, 2012.

Foudree A., Putarjunan A., Kambakam S. et al.: The mechanism of variegation in immutans provides insight into chloroplast biogenesis. - Front. Plant Sci. 260: 1-10, 2012.

Gabruk M., Stecka A., Strzałka A. et al.: Photoactive protochlorophyllide enzyme complexes reconstituted with PORA, PORB and PORC proteins of $A$. thaliana: fluorescence and catalytic properties. - PLOS ONE 10: e0116990, 2015.

Garland K.F.: Production of Heuchera and Coleus. - Master Thesis. Pp. 125. The University of Maine, Maine 2009.

Goodwin T.W.: The Biochemistry of the Carotenoids. Vol. I: Plants. Pp. 203. Chapman and Hall, New York 1980.

Gould K.S., Kuhn D.N., Lee D.W. et al: Why leaves are sometimes red. - Nature 378: 241-242, 1995.

Gould K.S, Neill S.O., Vogelmann T.C.: A unified explanation for anthocyanins in leaves? - Adv. Bot. Res. 37: 167-192, 2002.

Hatier J-H., Gould K.S.: Black coloration in leaves of Ophiopogon planiscapus 'Nigrescens'. Leaf optics, chromaticity, and internal light gradients. - Funct. Plant Biol. 34: 130138, 2007.

Henry A., Chopra S., Clark D.G. et al.: Responses to low phosphorus in high and low foliar anthocyanin coleus (Solenostemon scutellarioides) and maize (Zea mays). - Funct. Plant Biol. 39: 255-265, 2012.

Hlavinka J., Nauš J., Špundová M.: Anthocyanin contribution to chlorophyll meter readings and its correction. - Photosynth. Res. 118: 277-295, 2013.

Hughes N.M, Smith W.K.: Seasonal photosynthesis and anthocyanin production in 10 broadleaf evergreen species. Funct. Plant Biol. 34: 1072-1079, 2007.

Hung C.Y., Xie J.H.: A comparison of plants regenerated from a variegated Epipremnum aureum. - Biol. Plantarum 53: 610616, 2009.

Khoo H.-E., Prasad K.N, Kong K.-W. et al.: Carotenoids and their isomers: color pigments in fruits and vegetables. Molecules 16: 1710-1738, 2011.

Kim E.-H., Li X.-P., Razeghifard R. et al.: The multiple roles of light-harvesting chlorophyll $a / b$-protein complexes define structure and optimize function of Arabidopsis chloroplasts: A study using two chlorophyll $b$-less mutants. - Biochim. Biophys. Acta 1787: 973- 984, 2009.

Krause G.H., Weis E.: Chlorophyll fluorescence and photosynthesis. The Basics. - Annu. Rev. Plant Physiol. 42: 313-349, 1991.

Landi M., Tattini M., Gould K.: Multiple functional roles of anthocyanins in plant-environment interactions. - Environ. Exp. Bot. 119: 4-17, 2015

Lebowitz R.J.: The genetics and breeding of coleus. - Plant Breed. Rev. 3: 343-360, 1985.

Logan B.A., Stafstrom W.C., Walsh M.J.L. et al.: Examining the photoprotection hypothesis for adaxial foliar anthocyanin accumulation by revisiting comparisons of green- and redleafed varieties of coleus (Solenostemon scutellarioides). Photosynth. Res. 124: 267-274, 2015.

Liakopoulos G., Nikolopoulos D., Klouvatou A. et al:: The photoprotective role of epidermal anthocyanins and surface pubescence in young leaves of grapevine (Vitis vinifera). Ann. Bot.-London 98: 257-265, 2006.

Liakopoulos G., Spanorigas I.: Foliar anthocyanins in Pelargonium $\times$ hortorum are unable to alleviate light stress under photoinhibitory conditions. - Photosynthetica 50: 254$262,2012$.

Lichtenthaler H.K.: Chlorophylls and carotenoids: pigments of photosynthetic biomembranes. - Methods Enzymol. 148: 350382, 1987.

Lichtenthaler H.K, Babani F., Langsdorf G. et al.: Measurement of differences in red chlorophyll fluorescence and photosynthetic activity between sun and shade leaves by fluorescence imaging. - Photosynthetica 38: 521-529, 2000.

Matsubara A., Krause G.H., Aranda J. et al:: Sun-shade patterns of leaf carotenoid composition in 86 species of neotropical forest plants. - Funct. Plant Biol. 36: 20-36, 2009.

Maxwell K., Johnson N.G.: Chlorophyll fluorescence - a practical guide. - J. Exp. Bot. 51: 659-668, 2000.

Merzlyak M.N., Chivkunova O.B., Solovchenko A.E., Naqvi K.R.: Light absorption by anthocyanins in juvenile, stressed, and senescing leaves. - J. Exp. Bot. 59: 3903-3911, 2008.

Miyata K., Noguchi K., Terashima I. Cost and benefit of the repair of photodamaged photosystem II in spinach leaves: roles of acclimation to growth light. - Photosynth. Res. 113: 165-180, 2012.

Młodzińska E.: Survey of plant pigments: molecular and environmental determinants of plant colors. - Acta Biol. Cracov. Bot. 51: 7-16, 2009.

Montanaro G., Dichio B., Xiloyannis C.: Response of photosynthetic machinery of field-grown kiwifruit under Mediterranean condition during drought and re-watering. Photosynthetica 45: 533-540, 2007.

Muniz C.R, Freire F.C.O, Viana F.M.P et al.: Monitoring cashew seedlings during interactions with the fungus Lasiodiplodia theobromae using chlorophyll fluorescence imaging. - 
Photosynthetica 52: 529-537, 2014.

Nedbal L., Soukupová J., Whitmarsh J., Trtílek M.: Postharvest imaging of chlorophyll fluorescence from lemons can be used to predict fruit quality. - Photosynthetica 38: 571-579, 2000.

Neill S.O., Gould K.S. Anthocyanins in leaves: light attenuators or antioxidants. - Funct. Plant. Biol. 30: 865-873, 2003.

Nielsen S.L, Simonsen A.-M.: Photosynthesis and photoinhibition in two differently coloured varieties of Oxalis triangularis - the effect of anthocyanin content. Photosynthetica 49: 346-352, 2011.

Osman A.R.: Genetic variability and total phenolic compounds among six Coleus blumei varieties using RAPD Analysis. - J. Appl. Sci. Res. 9: 1395-1400, 2013.

Park S.U, Uddin M.R, Xu H. et al:: Biotechnological applications for rosmarinic acid production in plant. - Afr. J. Biotechnol. 7: 4959-4965, 2008.

Pineda M., Soukupová J., Matouš K. et al.: Conventional and combinatorial chlorophyll fluorescence imaging of tobamovirus-infected plants. - Photosynthetica 46: 441-451, 2008.

Porra R.J.: The chequered history of the development and use of simultaneous equations for the accurate determination of chlorophylls $a$ and $b$. - Photosynth. Res. 73: 149-156, 2002.

Schreiber U., Schliwa W., Bilger U.: Continuous recording of photochemical and non-photochemical chlorophyll fluorescence quenching with a new type of modulation fluorimeter. Photosynth. Res. 10: 51-62, 1986.

Sofo A., Dichio B., Montanaro G., et al.: Photosynthetic performance and light response of two olive cultivars under different water and light regimes. - Photosynthetica 47: 602-608, 2009.

Soni H., Singhai A.K.: Recent updates on the genus coleus: a review. - Asian J. Pharmac. Clin. Res. 5: 12-17, 2012.

Steyn W.J, Wand S.J.E, Holcroft D.M et al.: Anthocyanins in vegetative tissues: a proposed unified function in photoprotection. - New Phytol. 155: 349-361, 2002.

Takahashi S., Badger M.R.: Photoprotection in plants: a new light on photosystem II damage. - Trends Plant Sci. 16: 53-60, 2011.

Takayama K., Nishina H., Iyoki S. et al.: Early detection of drought stress in tomato plants with chlorophyll fluorescence imaging - practical application of the speaking plant approach in a greenhouse. - Preprints of the $18^{\text {th }}$ IFAC World Congress Milano (Italy). Pp. 1785-1790, Int. Feder. Automatic Control, Milano 2011.

Tanaka Y., Sasaki N., Ohmiya A.: Biosynthesis of plant pigments: anthocyanins, betalains and carotenoids. - Plant J. 54: 733-749, 2008.

Uddling J., Gelang-Alfredsson J., Piiki K. et al.: Evaluating the relationship between leaf chlorophyll concentration and SPAD-502 chlorophyll meter readings. - Photosynth. Res. 91: 37-46, 2007.

Wentworth M., Murchle E.H., Gray J.E. et al.: Differential adaptation of two varieties of common bean to abiotic stress. II. Acclimation of photosynthesis. - J. Exp. Bot. 57: 699-709, 2006.

Wetzel C.M., Jiang C.Z., Meehan L.J. et al.: Nuclear-organelle interactions: the immutans variegation mutant of Arabidopsis is plastid autonomous and impaired in carotenoid biosynthesis. - Plant J. 6: 161-175, 1994.

Wu D., Wright D.A, Wetzel C. et al.: The IMMUTANS variegation locus of Arabidopsis defines a mitochondrial alternative oxidase homolog that functions during early chloroplast biogenesis. - Plant Cell 11: 43-55, 1999.

Yamamoto H.Y, Bassi R.: Carotenoids: localization and function. - In: Ort D.R., Yocum C.F. (ed.): Oxygenic Photosynthesis: the Light Reactions. Pp. 539-563. Kluwer Academic Publishers: Dordrecht 1996.

Zhu X.Y., Wang S.M., Zhang C.L.: Composition and characteristic differences in photosynthetic membranes of two ecotypes of reed (Phragmites communis L.) from different habitats. - Photosynthetica 41: 97-104, 2003. 